\title{
Cell Surface Fucosylation Does Not Affect Development of Colon Tumors in Mice with Germline Smad3 Mutation
}

\author{
Steven E. Domino David M. Karnak Elizabeth A. Hurd \\ Department of Obstetrics and Gynecology, Cellular and Molecular Biology Program, \\ University of Michigan Medical Center, Ann Arbor, Mich., USA
}

\section{Key Words}

Carbohydrates · Colon cancer $\cdot$ Fucosyltransferase .

Glycosylation • Transgenic mouse · Transforming

growth factor- $\beta$ signaling • Ulex europaeus agglutinin-I •

$\alpha(1,2)$ Fucose

\begin{abstract}
Background/Aims: Neoplasia-related alterations in cell surface $\alpha(1,2)$ fucosylated glycans have been reported in multiple tumors including colon, pancreas, endometrium, cervix, bladder, lung and choriocarcinoma. Spontaneous colorectal tumors from mice with a germline null mutation of transforming growth factor- $\beta$ signaling gene Smad3 (Madh3) were tested for $\alpha(1,2)$ fucosylated glycan expression. Methods: Ulex europaeus agglutinin-I (UEA-I) lectin staining, fucosyltransferase gene Northern blot analysis, and a cross of mutant mice with Fut2 and Smad3 germline mutations were performed. Results: Spontaneous colorectal tumors from Smad3 (-/-) homozygous null mice were found to express $\alpha(1,2)$ fucosylated glycans in an abnormal pattern compared to adjacent nonneoplastic colon. Northern blot analysis of $\alpha(1,2)$ fucosyltransferase genes Fut1 and Fut2 revealed that Fut2, but not Fut1, steady-state mRNA levels were significantly increased in tumors relative to adjacent normal colonic mucosa. Mutant mice with a Fut2-inactivating germline mutation were crossed with Smad3-targeted mice. In Smad3 (-/-)/Fut2 (-/-) double knockout mice, UEA-I lectin
\end{abstract}

staining was eliminated from colon and colon tumors; however, the number and size of tumors present by 24 weeks of age did not vary regardless of the Fut2 genotype. Conclusions: In this model of colorectal cancer, cell surface $\alpha(1,2)$ fucosylation does not affect development of colon tumors.

Copyright $\odot 2007$ S. Karger AG, Basel

\section{Introduction}

Fucosylated oligosaccharides have been implicated in multiple cell-cell interactions in differentiation, development and malignancy $[1,2]$. Glycosylated cell surface markers are used in cancer diagnosis, and therapeutic approaches have been designed to attack cancer cells via their glycans [3]. While previous studies have identified several $\alpha(1,2)$ fucosylated oligosaccharides associated with cancer progression, definitive evidence of a crucial role for these cell surface epitopes in carcinogenesis is lacking.

In human colon adenocarcinoma, expression of the fucosyltransferase gene FUT1 has been found to correlate with malignant progression [4]. Steady-state mRNA levels of FUT1 were elevated approximately 40 -fold in all human colon adenocarcinomas tested and up to 340 -fold in tumor-derived cell lines, while variable increases in mRNA levels of up to $50 \%$ were seen in adenomatous pol-

\section{KARGER}

(c) 2007 S. Karger AG, Basel

Fax +4161306 1234 E-Mail karger@karger.ch www.karger.com www.karger.com/tbi
Steven E. Domino, MD, $\mathrm{PhD}$

6428 Medical Science I Box 0617

1150 W Medical Center Dr, University of Michigan

Ann Arbor, MI 48109-0617 (USA)

Tel. +1 734647 9562, Fax +1 734936 8617, E-Mail sedomino@med.umich.edu 
yps [4]. Transfection of a weakly tumorigenic rat colon carcinoma cell line with human FUT1 increased expression of $\alpha(1,2)$ fucose on CD44 polypeptide sequences encoded by exon V6 and concomitantly increased tumorigenicity of the cells in syngeneic rats and nude mice [5]. When a rat colon carcinoma cell line was transfected with antisense vectors for rat Fut1 and Fut2, opposite effects were found on tumorigenicity $[6,7]$. Specifically, cells transfected with an antisense vector to rat Fut 2 displayed decreased cell surface $\alpha(1,2)$ fucose on CD44 and decreased tumorigenicity. Cells transfected with an antisense vector to Futl were significantly more tumorigenic in syngeneic animals, but not in immunodeficient SCID mice. A potential counterreceptor for the $\alpha(1,2)$ fucose $\mathrm{H}$ antigen has been detected in rat colon cancer cells [8]. These data suggest a potential role for Fut1 and/or Fut2 and their cognate $\alpha(1,2)$ fucosylated products in malignant progression of several tumor types from rodents and humans.

Spontaneous colorectal tumors develop in mice carrying germline-inactivating mutations in the transforming growth factor- $\beta$ (TGF- $\beta$ ) signaling gene $\operatorname{Smad} 3$ (also called Madh3) [9]. It is not known whether these tumors express $\alpha(1,2)$ fucosylated glycans or fucosyltransferase genes. The data presented here examined colorectal tumors from these mice for Ulex europaeus agglutinin-I (UEA-I) binding, $\alpha(1,2)$ fucosyltransferase gene expression, and tested the importance of cell surface $\alpha(1,2) \mathrm{fu}$ cose in the progression of colon cancer by determining the extent of spontaneous colorectal cancer in Smad3null $(-/-)$ mice in the presence and absence of $\alpha(1,2) \mathrm{fu}-$ cosylated oligosaccharides. This was accomplished by crossing Fut2-targeted mice with Smad3-targeted mice.

\section{Materials and Methods}

\section{Animals}

Animal protocols were approved by the University of Michigan Committee on Use and Care of Animals. Smad3 (+/-) heterozygous mutant mice on the 129/T2SvEmsJ background were received from Parada and colleagues [9]. Mice were maintained under specific pathogen-free conditions, fed Purina chow 5001, and handled according to institutionally recommended guidelines. For the mutant mouse cross, the background of the Fut 2 mouse on the $129 \mathrm{X} 1 / \mathrm{SvJ}$ was estimated to be approximately $25 \%$ different compared to the $129 / \mathrm{T} 2 \mathrm{SvEms}$ ] background [10]. Therefore, to reduce the possibility of strain differences affecting tumor progression, Fut2 (+/-) heterozygous mutant mice (Fut2 ${ }^{\text {tm1Sdo }}$ [11]) on the 129X1/SvJ background were backcrossed for three generations to wild-type 129/T2SvEmsJ mice (The Jackson Laboratory, Bar Harbor, Me., USA; stock No. 002065).

\section{Lectin Staining}

Prior to tissue collection, wild-type control and mutant mice were terminally perfused with ice-cold PBS followed by $4 \%$ paraformaldehyde. The entire colon was removed, cut longitudinally, and rinsed in ice-cold PBS. Grossly visible tumors were excised, weighed, and placed in formalin at $4^{\circ} \mathrm{C}$ for up to 1 week. Tissues were processed in paraffin blocks for permanent sections. Staining with UEA-I biotin-conjugated lectin (EY Laboratories, San Mateo, Calif., USA) was processed in a DAKO Autostainer Immunostaining System (Carpinteria, Calif., USA) by the University of Michigan IPOX histology core. Reagents used were peroxidase blocking reagent (S2001), labeled streptavidin-biotin (DAKO LSAB+ System), liquid DAB+ (K3468), and antibody diluent (S3022) at a 1:40 dilution.

\section{Northern Blot Analysis}

Paired distal colon tumors and adjacent control colon sample were excised and flash-frozen from Smad3-null mice at 24 weeks of age. Total RNA was isolated by the guanidine isothiocyanate/ phenol method by homogenizing samples in $1 \mathrm{ml}$ of TRIzol (Gibco BRL) per $100 \mathrm{mg}$ of tissue following the manufacturer's protocol. Polyadenylated mRNA was then isolated by QIAGEN Oligotex midi mRNA columns. After estimating concentrations of the samples by absorbance at $260 \mathrm{~nm}, 2 \mu \mathrm{g}$ of mRNA was loaded per lane for Northern blot analysis. Blots were sequentially probed with $\left.{ }^{32} \mathrm{P}\right] \mathrm{dCTP}$ random-primed cDNA probes for Fut2 (214-bp probe [12]), control gene mouse cyclophilin-A (721-bp probe, Ambion mouse DECAprobe template 7375) and control mouse ribosomal protein L32 (113-bp probe purified from a HindIII digestion of Pharmingen mouse L32 housekeeping template 45181P) at a specific activity of $1-2 \times 10^{9} \mathrm{cpm} / \mu \mathrm{g}$ of DNA probe. Duplicated blots were probed with the Futl probe, an antisense RNA probe was generated by T7 RNA polymerase with $\left[{ }^{32} \mathrm{P}\right] \mathrm{UTP}$ at a specific activity of $\sim 1 \times 10^{10} \mathrm{cpm} / \mu \mathrm{g}$ of probe to quantify the paucity of Fut1 mRNA (228 bp probe 'C' [13]), followed sequentially by probing for cyclophilin-A and ribosomal protein L32. After hybridization, all blots were washed under high stringency at $65^{\circ} \mathrm{C}$ with $0.2 \times$ SSC and $0.2 \%$ SDS, then placed on a PhosphorImager screen for quantification (Molecular Dynamics).

Cyclophilin-A and ribosomal protein L32 were chosen for testing as potential internal standard controls since a search of NCI Cancer Genome Anatomy Project (CGAP) library browser showed no difference in expression of these two genes (cyclophilin-A: UniGene Hs.9880; L32: UniGene Hs.169793) in a human colon cancer cDNA library (NCI_CGAP_Co8) when compared to normal human colon (NCI_CGAP_Co3) by digital differential display. On experimental Northern blots, equivalent loading differences were seen with both control genes. Expression of L32 was chosen as an internal reference to standardize loading between samples. Relative expression in tumor versus control colon samples was compared by two-tailed t test $(n=4)$.

\section{Mutant Mouse Cross}

To generate double mutant mice, breeding pairs of Smad3 $(+/-)$ heterozygous mutant mice and Fut2 (+/-) heterozygous mutant mice were crossed (Fut2 and Smad 3 map to separate mouse chromosomes; Chr 7 and Chr 2, respectively). Heterozygous Smad3 (+/-) mice were chosen for the cross since Smad3 (-/-) homozygous null mice did not breed well. Eight breeding cages were maintained for 6-8 months to generate sufficient progeny to 
Fig. 1. UEA-I lectin staining of normal colonic mucosa and tumors of 24-week-old Smad3 homozygous null mice. The colons of Smad3 (-/-) null mice were prepared for UEA-I lectin immunohistology as described in Materials and Methods. Sections are oriented with the luminal surface at the top and submucosa below. a Nonneoplastic colon crypts with apical staining of goblet cells (bar $=20 \mu \mathrm{m}$ ). b Higher magnification of goblet cell granules (bar $=20 \mu \mathrm{m})$. c Abnormal crypts with UEA-I binding of apical surfaces and enclosed secretions (bar $=100 \mu \mathrm{m})$. d Adjacent control section stained identically to c except without UEA-I lectin showing little nonspecific staining (bar $=100 \mu \mathrm{m})$.
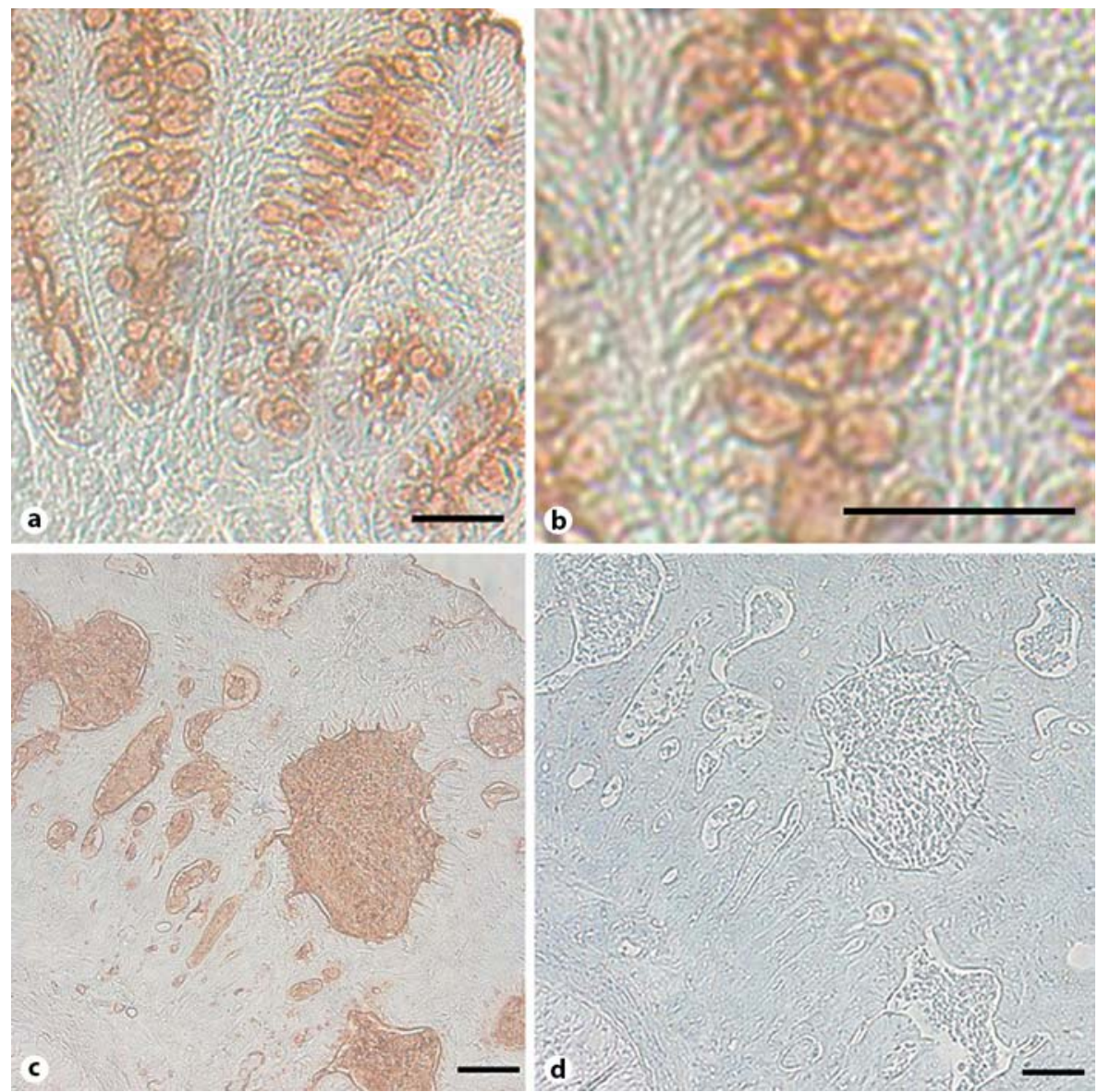

meet the number of mice estimated to be required in a prestudy power analysis. Genotyping was performed on all progeny by PCR using specific primers on tail tip DNA, and confirmed by a second DNA sample from ear tip biopsy in all Smad3 (-/-) null mice. Smad3 (+/+) wild-type and Smad3 (+/-) heterozygous progeny were euthanized. Smad3 (-/-) null mice were then genotyped for Fut 2 and housed until 24 weeks of age. Four animals that showed signs of distress (ruffled fur, rectal prolapse from tumor) were euthanized and tissues collected at 22-23 weeks of age, otherwise all mice were euthanized and tissues collected at 24 weeks.

\section{Results}

UEA-1 Lectin Staining and $\alpha(1,2)$ Fucosyltransferase Gene Expression Differ between Normal Colonic

Mucosa and Neoplastic Mucosa

Colon tumors of 24-week-old Smad3 (-/-) null mice were examined for expression of $\alpha(1,2)$ fucosylated epitopes by UEA-I lectin binding. Lectin staining in colonic tumors was associated with abnormal crypt secretions and cell surfaces. Adjacent nonneoplastic mucosa showed positive UEA-I binding concentrated in goblet cell granules (fig. 1). The locations of UEA-1 reactivity in Smad3 null mice were similar to differences in UEA-I binding between human adenocarcinomas and normal colonic mucosa [14]. We previously have shown that goblet cell granules are the predominant site of UEA-I reactivity in colon correlating with production of $\alpha(1,2)$ fucosylated mucin Muc2 secreted from goblet cells [15].

UEA-I binding is closely associated with both Fut 1 and Fut $2 \alpha(1,2)$ fucosyltransferase gene expression in secretory tissues including the colon, stomach, and uterus [11]. To determine which $\alpha(1,2)$ fucosyltransferase gene $(\mathrm{s})$ were expressed in tumors and the relative differences in steadystate mRNA levels between tumors and normal colon, Northern blot analysis was performed. Polyadenylated RNA samples were isolated from spontaneous colon tumors and adjacent normal colon from four Smad3 homozygous null mice as described under Experimental Methods. Gene-specific probes were utilized for three mouse 


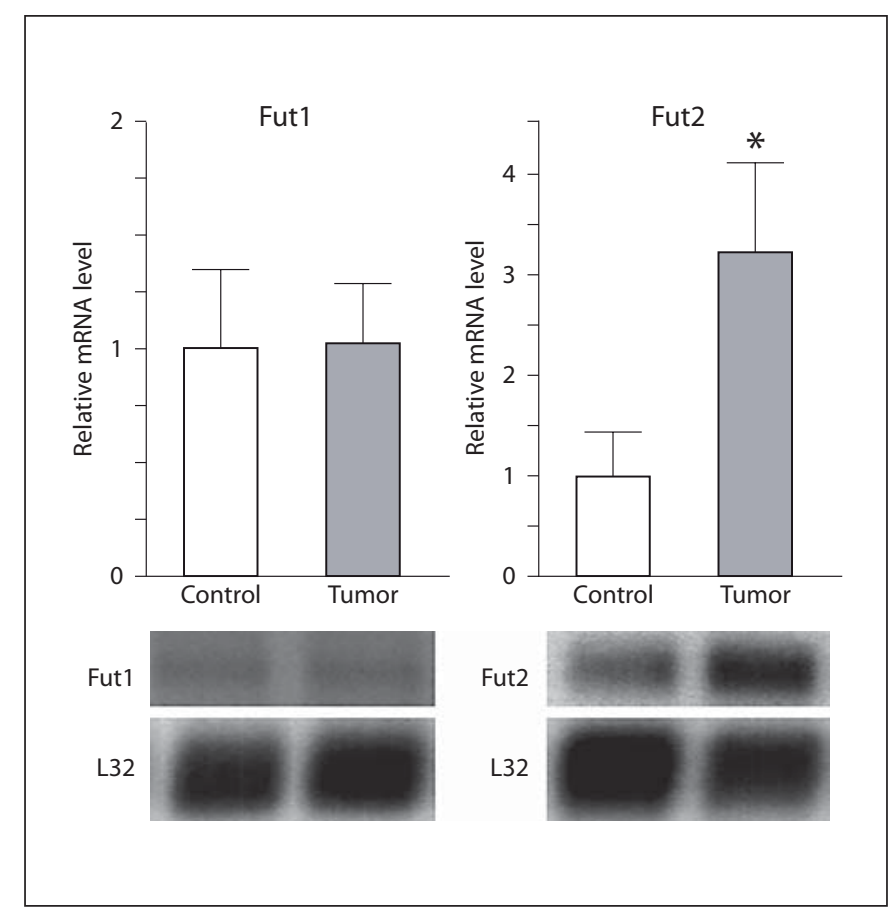

Fig. 2. Expression of Fut 1 and Fut 2 in distal colon tumors of 5 - to 6-month-old Smad3 homozygous null mice. Polyadenylated RNA was isolated from spontaneous colon tumors and normal colon from four Smad3 homozygous null mice. Two micrograms of polyadenylated RNA per lane were electrophoresed by formaldehyde agarose gel electrophoresis, transferred to nylon membranes, hybridized with gene-specific probes, and quantified by PhosphorImager. The columns display the mean \pm the standard deviation in relative mRNA expression between tumor and control colon samples. Statistically significant elevation of Fut 2 steadystate mRNA levels was found in tumors compared to adjacent normal colon $\left({ }^{*} \mathrm{p}<0.05\right)$. Sample autoradiographs for L32 control, Fut1 and Fut2 gene probes are shown below. $\alpha(1,2)$ fucosyltransferase genes, Fut1, Fut2, and Sec1. Fut1 steady-state mRNA levels did not differ between control colon and tumors while Fut2 steady-state mRNA levels were increased in colon tumors (fig. 2). Secl was not detected in normal colon or tumors (data not shown).

\section{Cross of Mice with Germline Mutations in Fut2 and Smad3 Produced Tumors That Lack UEA-I Binding but Do Not Vary in Number or Size Based on Fut2 Background}

To determine the importance of elevated Fut 2 expression in Smad3 -1- tumors, Fut2-targeted mice were crossed with Smad3-targeted mice. For generation of double mutant mice, breeding pairs of Smad3 (+/-) heterozygous mutant mice and Fut2 (+/-) heterozygous mutant mice were crossed. Smad3 (-/-) null progeny were genotyped for Fut 2 and categorized into Fut $2(+/+)$ wildtype control, Fut2 (+/-) heterozygous, and Fut2 (-/-) homozygous null. Tumor burden of Fut2 (+/-) Smad3 -/mice (experimental group 1) was predicted to be similar to Fut2 (+/+) Smad3 -/- littermates (positive control group). Double null Fut2 (-/-) Smad3 (-/-) mice were predicted to have decreased tumor burden (experimental group 2). To estimate the sample size needed for the number of mice required for the cross, the following assumptions were made: (1) average number of colon tumors per mouse of 3.8 with a range of 2-6 gross tumors and standard deviation of 1.15 [9], (2) amount of change in tumor burden deemed to be clinically significant: $50 \%$, and (3) an effect size of 1.65 (1.9 divided by standard deviation of 1.15). To detect with statistical significance a $50 \%$ increase or decrease in tumor burden with a power of 0.9
Fig. 3. UEA-I lectin staining of colon tumors of 24-week-old Smad3 (-/-)/Fut2 (-/-) double homozygous null mice. Colon tumors from mice with germline mutations of Smad 3 and Fut 2 were tested for UEA-I lectin staining. a Tumors Fut2 $(+/-) / S m a d 3(-/-)$ stained extensively with UEA-I lectin similar to tumors from Smad3 (-/-) mice with wild-type Fut2 $(+/+)$ expression (fig. 1$)$. b Tumors from double null Fut2 (-/-)/Smad3 (-/-) mice lack specific UEA-I staining indicating expression of Fut 2 is required to generate $\alpha(1,2)$ fucosylated epitopes ( $\operatorname{bar}=100 \mu \mathrm{m})$.
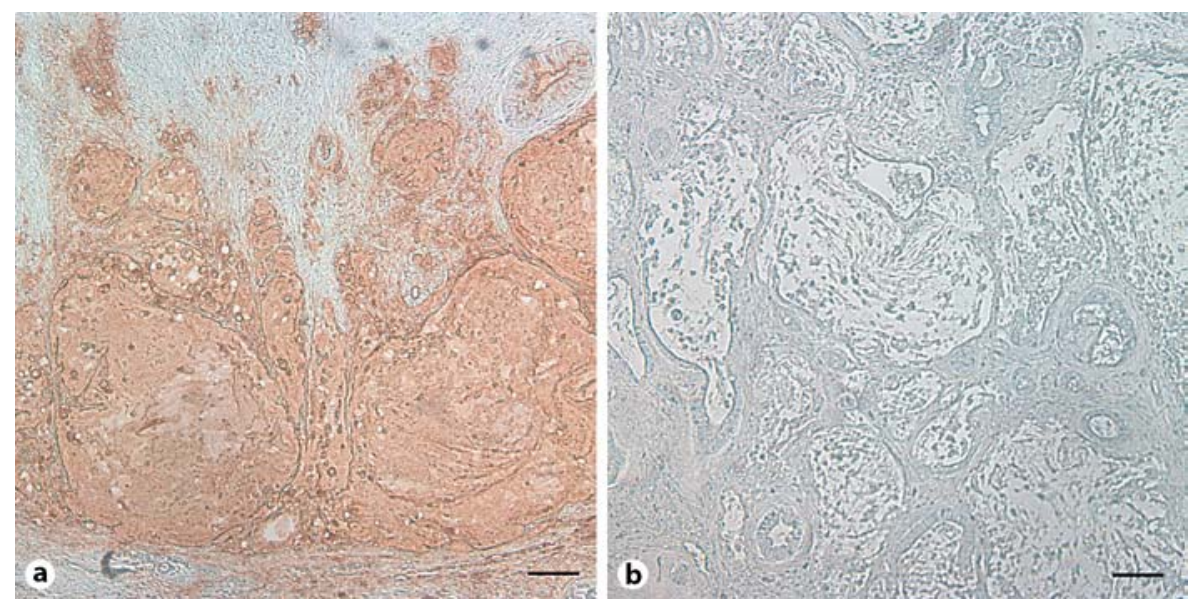
Table 1. Cross of mice with germline mutations of Smad3 and Fut2 comparing tumor number and size

\begin{tabular}{llll}
\hline Genotype: & $\begin{array}{l}\text { Control group } \\
\text { Fut2 }(+/+) / \operatorname{Smad} 3(-/-)\end{array}$ & $\begin{array}{l}\text { Experimental group 1 } \\
\text { Fut2 }(+/-) / \text { Smad3 }(-/-)\end{array}$ & $\begin{array}{l}\text { Experimental group 2 } \\
\text { Fut2 }(-/-) / \text { Smad3 }(-/-)\end{array}$ \\
\hline $\begin{array}{l}\text { Number of progeny } \\
\text { Number of mice with tumors }\end{array}$ & 12 & 21 & 10 \\
$\begin{array}{l}\text { Number of colon tumors per } \\
\quad \text { affected mouse }\end{array}$ & 5 & 12 & 5 \\
Average weight of tumors, mg & $1.4 \pm 0.5$ & $1.3 \pm 0.5$ & $1.2 \pm 0.5$ \\
\hline
\end{tabular}

and $\mathrm{p}<0.05,10$ animals were estimated to be required in each group.

Eight breeding cages were maintained for 6-8 months to generate sufficient progeny to meet the sample size estimated. The distribution of progeny obtained fit the predicted distribution for a Fut2 (+/-) heterozygous cross of approximately $25 \%$ wild type, $50 \%$ heterozygous, and $25 \%$ null suggesting no embryonic lethal effects from loss of the Fut 2 gene on the Smad3 null background. Tumors were obtained in all three genotypes of mice, confirming the original observation by Zhu et al. [9] that Smad3 $(-/-)$ mice develop spontaneous colorectal tumors, albeit at a lower penetrance $(\sim 50 \%)$ in the environment for this study.

In Smad3 (-/-)/Fut2 (-/-) double knockout mice, UEA-I lectin staining was eliminated from colon and colon tumors (fig. 3), indicating significant loss of $\alpha(1,2)$ fucosyltransferase function, although the Fut1 gene was not targeted in this experiment and a trace amount of $\alpha(1,2)$ fucosylated glycans may be present below the level of detection by UEA-I lectin. The number and size of tumors present by 24 weeks of age did not vary regardless of the Fut2 genotype (table 1). These data suggest in this genetic model of colorectal cancer that cell surface fucosylation does not affect development of colon tumors.

\section{Discussion}

Aberrant expression of fucosylated glycans has been detected in tumors from multiple tissues including pancreas [16], liver [17], endometrium [18], and colon [19, 20]. In at least some tumors, the mechanism appears to be an increased expression of glycosyltransferase enzymes [21-23]. To test the importance of glycosyltransferase expression in tumors, previous investigators have crossed mutant mice to observe the resulting effect on tumor development. With this approach, the relevance of $\mathrm{N}$-acetylglucosaminyl epitopes in breast cancer metastasis was shown by crossing $\beta(1,6) \mathrm{N}$-acetylglucosaminyl transferase $\mathrm{V}$ null mice with transgenic mice that develop metastatic mammary tumors [24,25]. Specific to human colorectal cancer, metastatic potential was shown to dramatically decrease in cultured cells deficient in the GDPfucose-generating enzyme FX, potentially by altered interaction of fucosylated glycans on colorectal cancer cells with the extracellular matrix [26].

Additional approaches to the study of colon tumors have included transfection of carcinoma cell lines with human fucosyltransferase genes to increase cell surface elaboration of $\alpha(1,2)$ fucose. Le Pendu and colleagues [5] found increased fucosylation of CD44 polypeptide sequences encoded by exon 6 and concomitantly increased tumorigenicity of the cells in syngeneic rats and nude mice upon transfection with human Fut1. Alteration of CD44v6 fucosylation has been suggested to mediate apoptosis of colon cancer cells since apoptosis induction was associated with decreasing $\alpha(1,2)$ fucosylated blood group antigen expression and fucosyltransferase activity [27]. In particular, all $\alpha(1,2)$ fucose-containing antigens (blood groups A, H and Lewis groups) showed a loss of expression, predominantly from CD44 glycoprotein. In a comparison of cell lines with differing extent of $\alpha(1,2)$ fucosylation and tumorigenicity, high expression of $\alpha(1,2)$ fucose was correlated with a decreased sensitivity to apoptosis [27]. Since elimination of mature cells in the gastrointestinal epithelium is likely mediated by apoptosis, impairment of apoptosis has been proposed to occur in close association with initiation of colon carcinogenesis [28].

Our study sought to determine if increased Fut2 expression evidenced in Smad3 knockout mice had an effect on tumor number, progression, or metastatic potency. By crossing Fut2 null mice with Smad3 nulls, we effectively eliminated $\alpha(1,2)$ fucosylation in the colon. If 
such fucosylation was an important factor in tumor progression, one would expect fewer or smaller tumors. Our results found no significant difference in tumor size or number between Smad3 nulls and Smad3/Fut2 double nulls. Unfortunately, our model system could not address effects on metastatic potential because mice sacrificed at 24 weeks for humane purposes had tumors localized to the mucosa. In our hands, Smad3 null mice displayed a tumor penetrance lower than originally reported. It should be noted that three lines of Smad3 null mice have been generated and only one of them, on the 129/ T2SvEmsJ background, develops colorectal tumors, therefore strain background has a significant effect on tumor formation $[29,30]$.

The potential mechanism for fucosyltransferase interaction with tumorgenicity is complicated by the variety of substrates and differing substrate specificity for the fucosyltransferase enzymes [31]. Fut1 and Fut2 enzymes can $\alpha(1,2)$ fucosylate a variety of glycans and glycolipids. In enzymic studies with natural and synthetic substrates, both enzymes were shown to be capable of adding $\alpha(1,2)$ fucose to both $\mathrm{H}$ antigen type 1 and type 2 acceptor substrates but with differing enzymatic kinetic parameters $[13,32]$. In pancreatic cancer cells, studies have postulated that increased $\alpha(1,2)$ fucosylation reduce metastatic potential by decreasing the adhesive properties due to altered sialyl Lewis antigen presented at the cell surface [33].

The data in the present study may also be influenced by effects on the immune system. Alteration of TGF- $\beta$ signaling in mice with germline mutation of $S \operatorname{mad} 3$ is not restricted to the colonic epithelium. In T cells, loss of TGF- $\beta$ signaling leads to abnormal differentiation and activation compromising mucosal immunity [30]. Goupille et al. [34] reported an effect of $\alpha(1,2)$ fucosylation on the in vivo growth of colon carcinoma cells in an experimental rat model. The effect was visible in immunocompetent animals only, whereas $\alpha(1,2)$ fucosylatransfer ase transfected cells and control cells grew similarly in immunocompromised animals. Likewise, an effect of $\alpha(1,2)$ fucosylation on immune escape may not be visible in Smad3 -/- mice.

The possibility exists that Fut2 overexpression in Smad3 nulls is an unimportant consequence of a tumorrelated cellular change. However, the converse could also be true, i.e. Fut 2 overexpression could be a compensatory change that decreases metastatic potency. In a future study, this question could be addressed by injecting tumor-derived cells from the experimental groups studied here into nude mice and analyzing tumor occurrence.

\section{Acknowledgements}

The authors would like to thank Luis Parada and Yuan Zhu for providing Smad3-targeted mice and personnel of the Cancer Center Research Histology and Immunoperoxidase Core at the University of Michigan for histological processing. This work was supported by the National Institutes of Health through grant K01 CA93856 and the University of Michigan's Cancer Center Support Grant (5 P30 CA46592).

\section{References}

1 Hart GW, Lowe JB, Sathyamoorthy N: Glycobiology and cancer: meeting summary and future directions. Cancer Biol Ther 2004;3:233-237.

-2 Varki A, Marth J: Oligosaccharides in vertebrate development. Semin Dev Biol 1995;6: 127-138.

3 Brockhausen I: Pathways of O-glycan biosynthesis in cancer cells. Biochim Biophys Acta 1999;1473:67-95.

4 Sun J, Thurin J, Cooper HS, Wang P, Mackiewicz M, Steplewski Z, Blaszczyk-Thurin M: Elevated expression of $\mathrm{H}$ type GDP-L-fucose:beta-D-galactoside alpha-2-L-fucosyltransferase is associated with human colon adenocarcinoma progression. Proc Natl Acad Sci USA 1995;92:5724-5728.
5 Goupille C, Hallouin F, Meflah K, LePendu $\mathrm{J}$ : Increase of rat colon carcinoma cells tumorigenicity by alpha(1-2)fucosyltransferase gene transfection. Glycobiology 1997;7: 221-229.

6 Hallouin F, Goupille C, Bureau V, Meflah K, Le Pendu J: Increased tumorigenicity of rat colon carcinoma cells after alpha1,2-fucosyltransferase FTA anti-sense cDNA transfection. Int J Cancer 1999;80:606-611.

7 Labarriere N, Piau J, Otry C, Denis M, Lustenberger P, Meflah K, LePendu J: H blood group antigen carried by CD44V modulates tumorigenicity of rat colon carcinoma cells. Cancer Res 1994;54:6275-6281.

8 Galanina O, Hallouin F, Goupille C, Bovin N, Le Pendu J: Detection of a potential receptor for the H-blood-group antigen on rat colon-carcinoma cells and normal tissues. Int J Cancer 1998;76:136-140.
-9 Zhu Y, Richardson J, Parada LF, Graff JM: Smad3 mutant mice develop metastatic colorectal cancer. Cell 1998;94:703-714.

-10 Threadgill DW, Yee D, Matin A, Nadeau JH, Magnuson T: Genealogy of the 129 inbred strains: $129 / \mathrm{SvJ}$ is a contaminated inbred strain. Mamm Genome 1997;8:390-393.

11 Domino SE, Zhang L, Gillespie PJ, Saunders TL, Lowe JB: Deficiency of reproductive tract alpha(1,2)fucosylated glycans and normal fertility in mice with targeted deletions of the FUT1 or FUT2 alpha $(1,2)$ fucosyltransferase locus. Mol Cell Biol 2001;21:8336-8345.

12 Domino SE, Zhang L, Lowe JB: Molecular cloning, genomic mapping, and expression of two secretor blood group alpha $(1,2)$ fucosyltransferase genes differentially regulated in mouse uterine epithelium and gastrointestinal tract. J Biol Chem 2001;276:2374823756. 
13 Domino SE, Hiraiwa N, Lowe JB: Molecular cloning and tissue-specific expression of a murine alpha(1,2)fucosyltransferase expressed in thymic and epididymal epithelial cells. Biochem J 1997;327:105-115.

-14 Yonezawa S, Nakamura T, Tanaka S, Sato E: Glycoconjugate with Ulex europaeus agglutinin-I-binding sites in normal mucosa, adenoma, and carcinoma of the human large bowel. J Natl Cancer Inst 1982;69:777-785.

-15 Hurd EA, Holmen JM, Hansson GC, Domino SE: Gastrointestinal mucins of Fut2-null mice lack terminal fucosylation without affecting colonization by Candida albicans. Glycobiology 2005;15:1002-1007.

- 16 Takiyama T, Woutersen R, Pour P: Ulex europaeus-I: a marker for differentiation of (pre)cancerous lesions induced in the rat pancreas by azaserine. Carcinogenesis 1988; 9:2087-2092.

-17 Sherwood AL, Holmes EH: Cloning and expression of the catalytic domain from rat hepatoma H35 cell GDP-fucose:GM1 alpha $1 \rightarrow 2$ fucosyltransferase, an enzyme which is activated during early stages of chemical carcinogenesis in rat liver. Arch Biochem Biophys 1998;355:215-221.

18 Ambros R, Kurman R: Association of Ulex europaeus agglutinin I binding with invasion of endometrial carcinoma. Int J Gynecol Pathol 1993;12:301-306.

-19 Valli M, Gallanti A, Bozzaro S, Trinchera M: Beta-1,3-galactosyltransferase and alpha1,2 -fucosyltransferase involved in the biosynthesis of type-1-chain carbohydrate antigens in human colon adenocarcinoma cell lines. Eur J Biochem 1998;256:494-501.
20 Hallouin F, Goupille C, le Cabellec M, Bara J, le Pendu J: Expression of $\mathrm{A}$ and $\mathrm{H}$ bloodgroup and of CD44 antigens during chemical rat colonic carcinogenesis. Glycoconj J 1997; 14:801-808.

21 Asao T, Nagamachi Y, Morinaga N, Shitara Y, Takenoshita S, Yazawa S: Carcinoma-related alterations of glycosyltransferases in human tissues. Cancer 1995;75:1539-1544.

22 Mas E, Pasqualini E, Caillol N, El Battari A, Crotte C, Lombardo D, Sadoulet MO: Fucosyltransferase activities in human pancreatic tissue: comparative study between cancer tissues and established tumoral cell lines. Glycobiology 1998;8:605-613.

23 Fukushima K, Hara-Kuge S, Seko A, Ikehara Y, Yamashita K: Elevation of alpha $\rightarrow 6$ sialyltransferase and alpha $1 \rightarrow 2$ fucosyltransferase activities in human choriocarcinoma. Cancer Res 1998;58:4301-4306.

24 Dennis JW, Granovsky M, Warren CE: Glycoprotein glycosylation and cancer progression. Biochim Biophys Acta 1999;1473:2134.

25 Granovsky M, Fata J, Pawling J, Muller WJ, Khokha R, Dennis JW: Suppression of tumor growth and metastasis in Mgat5-deficient mice. Nat Med 2000;6:306-312.

26 Zipin A, Israeli-Amit M, Meshel T, Sagi-Assif O, Yron I, Lifshitz V, Bacharach E, Smorodinsky NI, Many A, Czernilofsky PA, Morton DL, Witz IP: Tumor-microenvironment interactions: the fucose-generating FX enzyme controls adhesive properties of colorectal cancer cells. Cancer Res 2004;64:65716578.

-27 Rapoport E, Pendu JL: Glycosylation alterations of cells in late phase apoptosis from colon carcinomas. Glycobiology 1999;9:13371345.
28 Janin N: A simple model for carcinogenesis of colorectal cancers with microsatellite instability. Adv Cancer Res 2000;77:189-221.

29 Datto MB, Frederick JP, Pan L, Borton AJ, Zhuang Y, Wang XF: Targeted disruption of Smad3 reveals an essential role in transforming growth factor beta-mediated signal transduction. Mol Cell Biol 1999;19:24952504.

30 Yang X, Letterio JJ, Lechleider RJ, Chen L, Hayman R, Gu H, Roberts AB, Deng C: Targeted disruption of SMAD3 results in impaired mucosal immunity and diminished $\mathrm{T}$ cell responsiveness to TGF-beta. EMBO J 1999;18:1280-1291.

-31 Le Pendu J, Marionneau S, Cailleau-Thomas A, Rocher J, Le Moullac-Vaidye B, Clement $\mathrm{M}: \mathrm{ABH}$ and Lewis histo-blood group antigens in cancer. APMIS 2001;109:9-31.

-32 Bureau V, Marionneau S, Cailleau-Thomas A, Le Moullac-Vaidye B, Liehr T, Le Pendu J: Comparison of the three rat GDP-L-fucose: beta-D-galactoside 2-alpha-L-fucosyltransferases FTA, FTB and FTC. Eur J Biochem 2001;268:1006-1019.

33 Aubert M, Panicot L, Crotte C, Gibier P, Lombardo D, Sadoulet MO, Mas E: Restoration of alpha $(1,2)$ fucosyltransferase activity decreases adhesive and metastatic properties of human pancreatic cancer cells. Cancer Res 2000;60:1449-1456.

34 Goupille C, Marionneau S, Bureau V, Hallouin F, Meichenin M, Rocher J, Le Pendu J: Alpha1,2fucosyltransferase increases resistance to apoptosis of rat colon carcinoma cells. Glycobiology 2000;10:375-382. 